Since reading the above paper at the Academy I. saw the patient. He said he was perfectly well, and was looking out for occupation. He was perfectly free from head symptoms. Hence, I think I am justified in concluding that there was no intra-cranial aneurysm, and that the head symptoms were due to the dilated condition of the middle meningeal itself.

ArT. XX.-The Discovery of Modern Ancesthetics. By George M. Foy, F.R.C.S., Surgeon, Whitworth Hospital, Drumcondra; Hon. Fellow of the Southern Surgical and Gynæcological Association, U.S.A.

Trre genesis of modern anæsthetics is found in Priestley's Discovery of Oxygen. All attempts to produce anæsthesia prior to that brilliant discovery were unsatisfactory. With the introduction of "factitious airs," there arose a hope in the minds of certain members of the medical profession that in pneumatic medicine there was to be found a remedy for the greater number of diseases. Of those who held this view the most enthusiastic and one of the ablest was Dr. Thomas Beddoes. No man of that day was better fitted for the task than Beddoes, whom Humphry Davy, in 1798, described as "one of the most original men I ever saw . . . extremely silent, and, in a few words, a very bad companion."

Beddoes was fully abreast of the medical and chemical knowledge of his day. Whilst yet a medical student he translated Spallanzani's " Dissertations on Natural History," Bergmann's "Essays on Elective Attractions," and Gimbernaut's surgical monograph on "Hernia." From being the pupil he became the friend of Cullen, Black, and Lavoisier. $\mathrm{He}$ qualified as a Doctor of Medicine in 1786, and soon afterwards translated Scheele's "Chemical Essays," and in 1790 published "Chemical Experiments and Opinions," in which he endeavoured to obtain justice for the views and discoveries of Dr. Mayow in pneumatic chemistry; and to fully realise Black's objection to Sthal's theory of phlogiston he learned German. In 1792 he voluntarily resigned the position of reader of Chemistry in Oxford, of which he had been six years in possession, his Republican 
ideas having given offence to the university authorities. His success at Oxford as a lecturer was unparalleled. "The time of his residence there," says one of his pupils, "was a brilliant one in the annals of the university, and produced a taste for scientific researches that bordered upon enthusiasm."

The Hotwells Hospital was founded soon after his resignation at Clifton, Bristol, by the aid of a few friends, and made such rapid progress in public favour that Dr. Beddoes soon required an assistant to superintend his laboratory. This led, in 1798, to the appointment of Davy, whose introduction was brought about in the following fashion:Associated with Dr. Beddoes in the hospital was Mr. James Watt, the Engineer, whose son, Mr. Gregory Watt, took a great interest in pneumatic medicine, and was a frequent visitor to the hospital, as were the Wedgewoods, Southey, Coleridge, Wordsworth, Priestley, son of the discoverer of nitrous oxide, Tobin the dramatist, for whose five-act comedy Davy found time to write the prologue, and the Edgeworths. Mr. Gregory Watt was of a weakly, consumptive habit, and in 1797 he was ordered to winter in Penzance where he lodged with Mrs. Davy, a widow, boarding with the family. He met Humphry Davy, two years his junior, at the family table, and was pleased with the enthusiasm and diligence of the apprentice of Mr. Bingham Borlase, A pothecary and Surgeon, who had already mastered Lavoisier's "Elements of Chemistry."

Mr. Gregory Watt, finding benefit from the air of Penzance, and liking the Davy family, remained with them until the following summer. On his return to Clifton he suggested the engagement of Mr. Humphry Davy to Dr. Beddoes, and his recommendation was warmly supported by Mr. Gilbert, of Penzance, who had more than a local reputation as a chemist.

Mr. Humphry Davy was released from his apprenticeship by Mr. Borlase, who wrote on the back of his indenture that he released him from "all engagements whatever on account of his excellent behaviour," adding "because being a youth of great promise, I would not obstruct his present pursuits which are likely to promote his fortune and his fame."

He describes his journey to Bristol as "uncommonly 
pleasant . . Came into Exeter in a most joyful timethe celebration of Nelson's victory. The town was beautifully illuminated."

During the years immediately prior to Davy's arrival research had been pushed forward diligently at Hotwells.

On referring to Dr. Beddoes' book-"Considerations on the Medicinal Use, and on the Production of Factitious Airs"-we find that he had been experimenting on the lower animals with factitious airs from 1793, and that in 1794 he was freely using the different gases as therapeutic remedies as were Drs. Carmichael, Darwin, Ewart, Ferrier, Gamet, Johnstone, Pearson, Thornton, Trotter, and Withering.

An experiment to determine the physiological effect of oxygen was performed early in 1793 , and is attested by Messrs. Machell, Edgeworth, Guillemard, Sadler, and Beddoes. A large number of cases is given of the good efferts of the inhalation of oxygen gas in different parts of the country, and this method of treatment became popular. Almost every volatile substance came to be tried, and amongst others ether. Cullen in his lectures, which Beddoes attended, reconmended the vapour of ether as a local anæsthetic. The 1772 edition of his lectures gives full particulars for the use of the anæsthetic, and enumerates the class of cases in which he found it useful. Throughout Scotland ether came to be used by inhalation. Morris, of Edinburgh, writing in 1807, declares that-" In catarrhal and asthmatic complaints its vapour is inhaled with advantage." In England it was looked on with suspicion, for whilst Cullen was recommending it in Edinburgh, Lewis, of London (1768), writes-“" It has hitherto been regarded chiefly as a matter of curiosity, nor are its medicinal qualities as yet much known "-a prejudice which Beddoes did much to overcome.

Dr. Pearson, writing to Beddoes from Birmingham on the 2nd of February, 1795, says-"In my little publication I can scarcely call anything my own, but the observations on the vapour of ether, of the probable use of which . . . your considerations on factitious airs first gave me the idea."

In "Practical Synopsis" he writes:-_The vapour of vitriolic ether, whether pure or impregnated with cicuta, drawn into the lungs three or four times a day, has 
been found serviceable in cases of catarrh, phthisis pulmonalis, whooping congh, and croup. At each inhalation two or three teaspoonfuls of ether are used," and he refers the reader to Beddoes' writings.

And in a pamphlet published in 1795 :- " Under proper management, the application of modified airs to the lungs is perfectly safe and easy. The mixed airs are breathed out of bags, and no trouble or exertion is required on the part of the patient. That some of them possess very powerful and active properties is no objection to their use, for the same may be said of opium, and certain preparations of antimony and mercury, which are daily prescribed, and which only do mischief in the hands of unqualified persons. These airs, like all other medicines, may be overdosed, but practitioners who are acquainted with their effects, will take care that they are not too freely or too frequently applied. With such precautions, they may be pronounced to be as safe as most other medicines." He then adds :- " In consequence of the success which has already attended the medicinal application of factitious airs at Bristol and other places, a proposal has been made for the establishment of a Public Pneumatic Institution in London, for which subscriptions are now opened in this (Birmingham) and several other towns. Apparatus for obtaining the different kinds of airs have been introduced into the hospital and dispensary here (Birmingham), and in process of time, when the preparation and uses of these elastic fluids come to be generally understood, we may expect that these apparatus will be found in the laboratories of most of the apothecaries. Physicians will then have opportunities of prescribing the pneumatic treatment in all cases in which they may judge it to be proper."

From the above we see that the pneumatic treatment was known and practised years before $\mathrm{Dr}$. Beddoes knew of Mr. H. Davy's existence, and that almost all gases and volatile substances were being experimented with is abundantly clear from the medical records of the time.

Nor was Beddoes indifferent to the question of anæsthesia; he recognised that carbonic oxide gas stopped the pain of a blistered finger. He thus describes the experiment:- " The 
celebrated Dr. Inganhouse, in a letter dated August 4th, 1794, mentions to me a curious experiment ' which,' says he, 'if it be a real fact, throws a great deal of light upon your system; it is this:-Blister your finger so as to lay bare the naked and sensible skin, the contact of air will produce pain; put your finger into vital air, and that will give more pain; introduce it into fixed or azotic air, and the pain will diminish or cease.' Dr. Webster, he adds, was informed of these circumstances by a Frenchman whose name does not appear. I had of ten heard them indistinctly related, and it is rather surprising that the fact had not been ascertained. Much of the art of modern surgery consists in keeping the air from wounds and some kinds of ulcers, and this last fact, if the account be true, pretty decisively shows which ingredient of the atmosphere is injurious.

"I applied a blister an inch long and half an inch broad to the back of the third finger of the left hand. When the pain from the action of the cantharides entirely ceased, I cut away the scarf skin of the vesication, and was sensible, the moment the air was admitted, of a sharp, smarting pain. 'This did not continue so severe, but the exposed true skin sensibly smarted. Upon tying the neck of a bladder containing carbonic acid air from heated chalk round the root of the finger, the pain very soon subsided. While I kept my finger in carbonic acid air, which was near half an hour, I should not have known it received any injury."

And he adds:- "I have lately seen cancerous patients treated by the application of unrespirable air, with the most astonishing success. In mentioning to Dr. Black the introduction of factitious airs into the Bath hospital, as a source of hope, I did not so soon expect an event which ages and nations have desired in vain."

We now come to the employment of Davy and his first introduction to nitrous oxide gas experiments.

Contemporary with Beddoes was one Mitchell, a chemist, who published a Text-book on Chemistry in 1798, in which he asserted that nitrous oxide gas was a virulent poison, the probability being that his experiments were made with an impure sample; as he followed the earlier method of Priestley in its manufacture-exposing nitric oxide gas to the action 
of iron. Mitchell's statement greatly puzżled Beddoes, who had used oxygen gas and nitrogen gas, separately and mixed, without unpleasant results, and had the result of $\mathrm{Mr}$. James Watt's experiments with nitrous oxide, which corre. sponded with his own. Watt, on the 7th of October, 1794; writes of the inhalation of the gas_-"I had a slight though uncommon nausea, attended with some elevation of spirit all that evening, but no heat or thirst." With a suitable apparatus devised by Mr. James Watt, Beddoes decided to repeat Mitchell's experiments, and one of the first duties of $\mathrm{Mr}$. Humphry Davy was the preparation of nitrous oxide gas. In a letter from Davy to Mr. Gilbert, dated April 10th, 1799, he writes-"The gaseous oxide of azote is perfectly respirable. . . $I$ breathed to-day, in the presence of Dr. Beddoes and some others, sixteen quarts of it for near seven minutes," and he adds, "We have upwards of eighty out-patients in the Pneumatic Institution, and are going on wonderfully well."

Dr. Beddoes gave the result of the experiments to the world in Nicholson's Journal, and the institution became more than ever popular. "Laughing gas" became fashionable. Davy calculated that an exhilarating dose of the gas could be supplied for $2 \mathrm{~d}$., and it came to be so generally used as to be described as a national vice, and was the subject of a cartoon by Gillray. In all stages of depression or pain, the gas was resorted to as a remedy. Beddoes found it efficacious in arresting the pain of toothache. Davy took it to get poetic inspiration, and, finally, to cure the pain of a cutting wisdom-tooth, and finding it stopped the pain declared that-" As nitrous oxide in its extensive operation appears capable of destroying physical pain, it may probably be used with advantage during surgical operations in which no great effusion of blood takes place."

Davy's first experiment with nitrous oxide gas was made on the 9th of April, 1799, five years after its discoverer, Priestley, had sailed for America.

The inhalation of the gas quickly became a pastime in the Hotwells Hospital. Maria Edgeworth, who was on a visit with her sister, Anna, Mrs. Beddoes, writes :- "A young man, a Mr. Davy, at Dr. Beddoes', who has applied himself much to chemistry, has made some. discoveries of importance, and 
enthusiastically expects wonders will be performed by the use of certain gases, which inebriate in the most delightful manner, having the oblivious effects of Lethe and, at the same time, giving the rapturous sensation of the Nectar of the Gods! Pleasure even to madness is the consequence of this draught."

Davy's knowledge of chemistry when he came to Beddoes may fairly be estimated by his two essays in "Contributions to Physical and Medical Knowledge," published in 1794. Of them Dr. Thorpe writes: "Now-a-days such writings would hopelessly damn the reputation of any young aspirant for scientific fame, for it is indeed difficult to believe, as we read jaragraph after paragraph, that their author had any real conception of science, or that he was capable of understanding the need or appreciating the value of scientific evidence."

The opportunities for study in the Hotwells Hospital were not lost on Davy, and his later papers to the journal of "Physical and Medical Knowledge" are very different to his first crude contributions of 1799 .

Fortunate in having voiced the views of Beddoes and his fellow-workers on the anæsthetic properties of nitrous oxide, Davy to-day receives the credit of having discovered them, and to the general public the name of Thomas Beddoes, the real discoverer, is practically unknown. Beddoes, the chemist, physician, philanthropist, is almost forgotten, although it was in his laboratory and in his hospital that modern anæsthetics were born.

The engagement of Mr. Davy left Dr. Beddoes more time for the study of consumption, the cure or prevention of which was the labour of his life. Thus he writes in "Hygeia :"- "Should it be asked, in what manner is the existence of every person born and continuing to reside in the British islands most likely to terminate, the following table will supply the answer."

He then gives the years' bills of mortality, that for 1799 show that of 23,068 deaths, 5,721 were from consumption, 2,712 from fevers, and 2,400 from smallpox. Thus when Beddoes was engaged in the all-important study of the therapeutics of consumption, Mr. H. Davy, in testing the accuracy of Mitchell's experiments, had furced on. him the 
knowledge of the anæsthetic properties of nitrous oxide, and in a happy moment published the fact.

Mr. Humphry Davy's later papers on chemistry attracted the notice of Mr. B. Thompson, better known by his German title, Count Rumf ırd, who offered him the post of Assistant Professor of Chemistry in the Royal Institution, London, of which he was the founder. Davy was liberated from his engagement by Beddoes, and accepted the appointment, in succession to Mr. Thomas Garnett.

In the first year of the century, 1801, Mr. Davy commenced those brilliant lectures on which his great reputation rests; but from 1801 anæesthetics found no place in his studies.

The inhalation of nitrous oxide gas eame to be a pastime with the fashionable and idle loungers about town; and its production after a time was discontinued by Beddoes, who, failing in health and disappointed in not realising his hopes in pneumatic medicine, died broken-hearted in 1808 , in the forty-eighth year of his age. Writing to Davy from his death-bed he describes himself as "one who has scattered abroad the avena fatua of knowledge, from which neither branch, nor blossom, nor fruit has resulted."

But his talents were not altogether unrecognised. An obituary notice in the Edinburgh Medical and Surgical Journal thus concludes:- " The reputation of Dr. Beddoes as a physician has not yot attained o high a rank as is deserves. There is an ardour of talent, an animating earnestness, a stimulant exaggeration in his writings, well adapted to rouse the torpor and provoke the attention of medical readers. He had the mind of a poet and a painter, and displayed the power of his imagination in vivid representations of facts and theories. He was a pioneer in the road to discovery."

"I feel," wrote Coleridge ot hearing of his death, "that more had been taken out of my life by this than by any former event."

"From Beddoes," wrote Southey on the same oceasion, "I hoped for more good to the human race than any other individual."

In America, as in England, the inhalation of the gas 
became a popular amusement, and the name " laughing gas" tells that, for a time at least, the medicinal properties of the oxide were forgotten. How common the exhibition of laughing gas became is shown by Dr. Oliver P. Hubbard's paper, read before the New York State Medical Association on the 9 th of October, 1888 , to wit:-

"About sixty-seven years ago Dr. Stockman, a German druggist of Utica. came to Rome, Oneida county, to exhibit the well-known effects of its inhalation to a large number of people, on the evenings of November 5, 6, and 7, 1821, in the hotel and county courthouse. On the first evening occurred an incident still fresh in my memory, which I have frequently cited to my classes. I have sought in vain to discover a record of a case of an earlier date. I have always intended to publish this case, and during these years, to fortify my own impressions, I have procured from living witnesses written confirmation of all my recollections.

"My elder brother, William G. Hubbard, then sixteen years old, was present at Dr. Stockman's exhibition, and was one of those who took the gas. On the 14th of October, 1852, I wrote to him at Elgin, Ill., sending a copy of entries made at the time in my school journal, and adding, in substance, 'Now I will relate from memory. On the first evening, when the exhibition was closed (the doctor saying there was no more gas), and while many were standing around the fire talking over the occurrences, the doctor went into the dressingroom on the north, and found a young man lying on the floor close by the gasometer, entirely senseless.

" ' $\mathrm{He}$ had gone in stealthily, turned the stop-cock, and taken his fill, and here was the legitimate result-a case of complete anxsthesia, probably the first by this means ever authenticated.

“ 'The alarm was great. Death seemed imminent, if not present. He was lifted with difficulty by two persons, one under each arm, and brought into the large ball-room; and, after long and anxious suspense, he came to his natural state unharmed. How long he had been under the influence of the gas could not be known, for " the sweet was stolen." Can you recall this singular incident and those connected with it?' 
"On the 22nd he replies :-

“ 'I well remember old Dr. Stockman's performances at Rome. Your recollections, as far as you express them, agree almost exactly with my own. I do not know the name of the person; but that, I suppose, is not material. He was found as you mention, lying insensible with his mouth applied to the faucet. No means were applied to restore him to consciousness. He was brought ont into the ballroom, and a crowd immediately gathered around, watching the case.

" 'After a few. minutes his feet began to move slightly, with a gradually increasing motion to a very rapid one, evidently making an effort to dance. He was thus held up by the arms, with his feet flying like drumsticks, and gradually recovering the use of his limbs until he could dance alone.

" ' He danced in this way until the effect of the gas had subsided, and then appeared entirely exhausted. No injurious or unpleasant effect was noticed, and after resting a while he appeared as usual.'

"In November, 1883, I addressed a similar letter to an early friend and schoolmate, Mr. William E. Wright, all his life a resident of Rome, to which he replied as follows :-

" ' In answer to your inquiries, I would say that I remember the incidents as to the lecture of Dr. Stockman at the hotel ball-room, not from personal presence, but from my father, who was there, of an attack made upon him by Ephraim Smith when under the influence of the gas, who chased him from the ball-room into and through adjoining rooms until he came to himself again. I' also remember the case of the persen who became avercharged at the gasometer. I remember the lecture at the court-house from personal presence, and witnessed the agility of one man (M·Donnell), who, under the influence of the gas, immediately started on a run upon the top rails of the right hand tier of rising slips up through the people therein, causing great excitement and fear by the people, who seized and held him by force until he came out of the gas influence. Finding himself so held he was extremely mortified at his act and condition.'

"In August, 1887, wishing to confirm as far as possible the above recitals, I obtained from my cousin, Rev. Charles 
P. Grosvenor (Yale, 1827), of Pomfret, Conn., his recollections of these events, which occurred when, a boy of sixteen, he was at school in Rome. They coincide with the preceding; and he adds, "When thus held up and reviving, the young man would throw his feet as high as his head.'

Fortunately for medicine, the discovery of modern anæsthetics fell to the lot of gifted scientists.

The first manifestations of the anæsthetic properties of nitrous oxide were noted by Davy, Beddoes, Priestley, son of the discoverer of the gas, and Watt.

Davy thus recorded the effects:- "Having previously closed my nostrils and exhausted my lungs, I breathed four quarts of nitrous oxide from and in to a silk bag. 'The first feelings were similar to those produced in the last experiment; but in less than half : a minute, the respiration being continued, they diminished gradually and were succeeded by a sensation analogous to gentle pressure on all the muscles, attended by a highly. pleasurable thrilling, particularly in the chest and extremities. The objects around me became dazzling, and 'my hearing more acute. Towards the last inspiration the thrilling increased, the sense of muscular power became greater, and at last an irresistible propensity to action was indulged in; I recollect but indistinctly what followed; I know that my motions were'various and violent. These effects very soon ceased after respiration. In ten minutes $I$ had recovered my natural state of mind. The thrilling in the extremities continued longer than the other sensations. This experiment was made in the morning; no languor or exhaustion was consequent; my feelings throughout the day were as usual, and I passed the night in undisturbed repose."

The importance of the discovery of a general anæsthetic agent was not recognised; neither Dr. Davy nor Dr. Paris mention it prominently in their biographies of Sir Humphry Davy, and when the knighthood was conferred on him in 1812 no reference is made to the part he played in the discovery of anæsthetics.

Priestley, in America, gave himself up to theological sterlies, and Watt attained so much distinction as the inventor of the steam-engine that few remember the part he played in 
the birth of anæsthetics, and neither Cavendish, in England, nor Berthollet, in France, paid any attention to the great discovery; they were engaged in the study of chemistry for its own sake; withal, it is strange that Berthollet, as physician to the Duke of Orleans, did not, during his exhaustive studies of the gaseous elementary bodies, give some thought to the anæsthetic properties of nitrous oxide. Even Antoine Fourcroy, who with Vauquelin devoted so much study to the physical properties of the gas, and to the study of the chemistry of ether, gave no thought to the known anæsthetic properties of these substances. After 1803, however, Fourcroy's time was occupied with his administrative duties as Minister of Education under the First Consul. So completely had the remembrance of the anresthesia of nitrous oxide passed from memory that forty years after its property of preventing pain during surgical operations had been demonstrated in the Hotwells Hospital, Velpeau, of Paris, described the attempts to find such an agent chimerical.

From the re-introduction of the gas as an anæsthetin, Gardiner Quincy Colton plays such an important part that a short biographical sketeh of his career will not be amiss.

Gardiner Q. Colton was born in the village of Georgia, State of Nermont, on the 7th of February, 1814. He was the twelfth child of Walter Colton, one of the pioneer settlers of the State; he received a common school education, and at the age of sixteen learned the trade of chair-making, which he followed at Saint Albans until 1835, when he went to New York, worked at his trade, and wrote for the press. In 1842 he stadied medicine with Dr. William Parker, and attended the medical classes of the College of Physicians and Surgeons. In 1844 he began the delivery of philosophical and chemical lectures, giving exhibitions of electrieal phenomena, and of the effects of nitrous oxide or "laughing gas," and in his peregrinations, reached Hartford, Connecticut, where he delivered the celebrated lecture which Horace Wells turned to such account for humanity.

Leaving Wells to the study of the anssthetic, Colton continued his tour, giving, however, most of his attention to electricity, and in 1847, when leeturing in Pittsburg, be demonstrated its value as a motor power by pro- 
ducing an electro-motor car. Two years afterwards he joined the army of emigrants for California, at the instigation of his brother Walter, who was successively Professor of Moral Philosophy and Belles-Lettrès at Middleton, Connecticut, editor of a newspaper, chaplain in the U.S. Navy, Californian pioneer, Alcade of Montery, and is credited with having built the first sehool, established the first newspaper, and of having made the first public announcement of the discovery of gold, which he did in: a letter to the North American.

Neither as a miner nor as a physician was Gardiner. Quiney Colton a success in California, and he left the State in 1850 for the New England States, where he resumed his: lecturing tours until the outbreak of the civil war in 1860 , when he published a series of war-maps.

In 1863 he founded the "Colton Dental Association," having establishments in New York and several of the larger cities of the Union. The Dental Association was a success, and Colton turned his thoughts to the Old World, where the use of nitrous oxide gas had not "caught on."

In 1867 he arrived in Paris, where, through the influence. of an American dentist, Evans, the gas was brought under the notice of French surgeons and dentists.

Although Gardiner Q. Colton visited France I can find no mention of his having visited England. Dr. Evans brought his nit rous oxide apparatus to England, with which: the anæsthetic property of the gas was demonstrated at the Dental Hospital, London, on the 31st of March, 1868.

Horace Wells, to whom we are indebted for the reintroduction of the gas as an anasthetic, was a native of Hartford, Windsor County, State of Vermont. $\mathrm{He}$ studied dentistry in..Boston, and at the age of twenty-one (1836) commeneed the practice of his profession in Hartford, Conneeticut. His mind was early turned to the subjeet of preventing pain in the extraction of teeth. In August, 1840; Dr. L. P. Brockett, of Brooklyn, New. York, then a medical student, went to Wells to have a molar tooth extracted; the operation was difficult, and so painful that Wells suid there ought to be some method of mitigating such,suffering, and he thought a man might be. 
made so drunk by the inhalation of nitrous oxide gas as to prevent the pain of dental and other operations.

On the 10th of December, 1844, Mr. Gardiner Q. Colton delivered a lecture on " laughing gas" in Hartford, Conn., and after headministered the gas to Wells and severalother gentlemen, one of them, a Mr. Cooley, while under its influence, fell over some benches, and was evidently badly injured; when he returned to consciousness Wells rushed to him and inquired if he were hurt. He replied, "No." Wells then said, "You must have been hurt, for you struck your legs against the benches." The young man then, at Wells' suggestion, pulled up his trousers; the blood was running down his legs, and his knees were badly injured. . When again questioned by. Wells, he said, "I did not feel any pain at the time." Wells then turned to a friend, Mr. David Clarke, who was near by, and an eye-witness to all this, and remarked, "I believe a man by taking that gas could have a tooth extracted or a linab amputated without feeling the pain." So thoroughly was Wells convinced of this fact that he-told his wife on their way home that he intended to have the gas the next day, and have a tooth extracted. On arriving home, he left his wife and went to see his friend Dr. Riggs to announce his great discovery, and his intention to take the gas for the extraction of a tooth. Riggs tried to dissuade him from it, but his mind was made up, and he said, "As the young man did not feel pain at the time he was hurt, why cannot the gas be used in the extraction of teeth?"

Early next morning, the 11th of December, Wells called on Colton, and engaged him to ga to his office at 10 o'clock and give him the gas. He did so, and Dr. Riggs extracted a large molar tooth for Wells while under the influence of the gas. Wells did not seem to feel any pain. He remained unconsciuus for a few moments, and on coming to he exclaimed, “A new era for tooth-pulling! It did not hurt me more than the prick of a pin. It is the greatest discovery ever made."

For the moment Wells' enthusiasm was unbounded, He immediately began the administration of the gas, and daily extracted teeth under its influence, and other dentists in Hartford adopted the same practice with the same success. 
Dr. Marcy, then of Hartford, on witnessing Wells' operation, told him that when a student at Amhert College, he, with other students, had for amusement often inhaled nitrous oxide gas, and also the vapour of sulphuric ether, and that the effects of the two were identical, and he suggested to Wells to try ether as a substitute for gas. On this hint Wells tried it. He inhaled it himself, and he says, "I found it very difficult to inhale the vapour of ether in consequence of the choking sensation. For this reason, and for the reason that Dr. Marcy and myself came to the conclusion that nitrous oxide gas was not so liable to do injury, resolved to adhere to this alone."

Wells continued the use of the gas, and the dentists Riggs, Terry, Braddock, and Comfort; and the doctors in Hartford were well convinced of its value as an anæsthetic.

But, as Marion Sims writes (Virqinia.Medical Monthly), Wells felt that his great discovery should be laid more broadly before the profession and the world, and early in 1845 went to Boston for this purpose. Through his former pupil and partner, Dr. W. T. G. Morton, dentist, he was introduced to Dr. John C. Warren, Dr. Charles T. Jackson, Dr. Hayward, and others. Dr. Warren received him kindly, and Wells remained in Boston several days with the expectation of giving gas to a man who was to submit to an amputation at the hands of Dr. Warren. For some cause the operation was postponed. Wells was then invited to address the class at the medieal college on the subject. He did so at some length, and then administered the gas for the extraction of a tooth. Unfortunately the gas-bag was removed too soon, the patient was not sufficiently anrsthetised; he sereamed out and said he felt the pain of extraction, and the experiment was, therefore, a failure. Wells was hooted at, and unfeelingly hissed out of the operating theatre, pronounced a charlatan, and his anæsthetic a humbug. He retumed home, greatly mortified at his failure, was taken suddenly ill, and did not recover his health for many weeks.

His denunciation as a cbarlatan was due to the fact that the students thoughtlessly looked on him as one of the class of itinerant lecturers on electro-biology, suggestion, or mes- 
merism. Side by side with the chemical lecturer who demonstrated the stimulating effects of "laughing gas," was the mesmerist who by suggestion and chicanery amused his audience. At the very time Wells was claiming anæsthetic properties for nitrous oxide gas, operations were being performed on hypnotised patients. By some fatality the gas never appeared to the public to be worthy of serious consideration. Gillray published his celebrated caricature, "New Discoveries in Pneumatic Medicine," on the 2ŝrd of May, 1802, in which he represents Dr. Garnett, lecturer on chemistry, assisted by Mr. Humphry Davy, practically demonstrating his discourse by experiments on Sir J. C. Hippesley, through whose body the gas appears to pass as freely as it enters his mouth. The droll head of Count Rumford is discovered near a cabinet of electric apparatus ; behind the Count appears the hawk-like beak of Isaac D'Israeli. Near Lord Stanhope (in top boots, and leaning on a stick) is a pamphlet-" Hints on the nature of air required for the New French Diving-Boat." Lord Stanhope's immediate neighbours are understood to be Earl Pomfert and Sir Henry Englefield. Among the persons interested are Miss Lock, Mr. Southby, Mr. Denys (with a maul-stick and palette, holding his little boy), Lady Charlotte Denys, Mr. Thodal, a German atlaché, and several others. Mesmerism never suffered such fierce ridicule.

From 1830 to 1856 mesmerism, or as it was now called, hypnotism, had, principally owing to the writings of Mr. James Braid, of Manchester, shaken off charlatanism, and, clothed in scientific robes, appeared as the much-desired anæsthetic. Under its influence Esdaile performed three hundred capital operations of every description, and many of them of the most terrible nature, without inflicting pain on the patients. Cloquet and Broca also operated under the influence of hypnotism. Braid published his "Physiology of Fascination," and "Suggestion" became recognised as a useful therapeutic agent.

The great majority of the medical profession were opposed to mesmerism, no matter what name it bore; withal, a few prominent members decided to fairly test the 
value of "Suggestion" as a remedy. Amongst these was Dr. Gibbs, of South Carolina, of whom Dr. Grandy (Virginia Medical Monthly) writes:- "He and others claimed to have witnessed operations on patients mesmerised, and declared that mesmerism was the ne plus ultra needed to kill pain in surgical operations."

\section{VACCINATION IN INDIA.}

The Indian Medico-chirurgical Review summarises the state of Vaccination in the Central Provinces, India, in 1894-95. The figures may be taken as representative in this department of Indian hygiene. The population of the province is $12,131,300$. The number of primary vaccinations was 416,085 , an increase of 39,904 . Re-vaccinations were 54,507. "Of the total of 470592 , there were 401,186 successful primary vaccinations and 42,612 successful re-vaccinations, giving a per-centage of 96.42 of the former, and of 78.18 of the latter. The average number of operations performed by each vaccinator is stated to be 78.18 . During the year compulsory vaccination was extended to nine municipal towns."

TUBERCULOSIS COMMUNICATED BY A SPARROW.

Aт a recent meeting of the Société de Biologie (reported in the Gazette Médicale de Paris), M. Durante mentioned a case in which a woman had been pecked on the finger by a sparrow. Lupus developed at the wound, and glands at the bend of the elbow were secondarily affected. The tuberculous nature of the lesions was demonstrated by extirpation and inoculation. It was suggested that the bird had been infected from the corpse of a patient who had died of tuberculosis.

\section{WORKING WOMEN.}

We earnestly recommend to the notice of all who love to help and teach and encourage the "working woman," Miss Bessio Bernard's Scattered Leaves for Working Women, a little pamphlet published by James Montgomery, Londonderry. It is a paper read by the author at a Working Girls' Club; and it sems to us eminently suited to its purpose, and to its audience. It is full of sympathy and practical advice, and completely free from the tone of condescension which is so apt to mar the best-meant efforts to improve our fellow-creatures. 